\title{
Expression of plasminogen activator inhibitors type-1 and type-2 in the mouse lung after administration of crystalline silica
}

\author{
C. Lardot*, M. Heusterpreute+, P. Mertens*, M. Philippe+, D. Lison*
}

Expression of plasminogen activator inhibitors type-1 and type-2 in the mouse lung after administration of crystalline silica. C. Lardot, M. Heusterpreute, P. Mertens, M. Philippe, D. Lison. CERS Journals Ltd 1998.

ABSTRACT: Altered expression of plasminogen activator inhibitors (PAIs) is of potential relevance to the process of lung fibrosis. To clarify the involvement of PAIs in interstitial lung diseases, we examined whether alterations in PAI-1 and PAI-2 were induced in response to a single intratracheal administration of a fibrosing dose of crystalline silica in mice ( $\left.5 \mathrm{mg}^{-a n i m a l}{ }^{-1}\right)$.

The time course of changes in PAI activity and PAI-1 protein were characterized in bronchoalveolar lavage fluid (BALF) and changes in PAI-1 and PAI-2 messenger ribonucleic acid (mRNAs) were monitored by reverse transcriptase polymerase chain reaction (RT-PCR) in BALF cells and lung tissue up to the fibrotic stage of the disease.

Substantial levels of PAI activity were found in BALF of control animals, whereas no PAI-1 protein was detected. In response to silica treatment, we observed an acute increase of PAI activity and PAI-1 protein levels in BALF (day 1), associated with an induction of PAI-1 and PAI-2 mRNA levels in lung tissue. In alveolar macrophages, silica treatment induced a persistent upregulation of PAI-2 mRNA only. One month after silica treatment, PAI activity was undetectable in BALF while substantial PAI activity was still present in controls. At the same time point, sustained upregulation of PAI-1 and PAI- 2 mRNAs was, however, noted in lung tissue of animals treated with silica.

These findings support the possible implication of PAIs in the remodelling process induced by silica in the lung.

Eur Respir J 1998; 11: 912-921.
*Industrial Toxicology and Occupational Medicine Unit, School of Medicine, and +Laboratory of Clinical Molecular Biology, Catholic University of Louvain, Brussels, Belgium

Correspondence: C. Lardot

Industrial Toxicology and Occupational Medicine Unit

Clos Chapelle-aux-Champs, Box 30.54

1200 Brussels

Belgium

Fax: 3227643228

Keywords: Messenger ribonucleic acid analysis

particle-induced lung injury

plasminogen activator inhibitors

Received: July 91997

Accepted after revision January 101998

Supported by grant No. EV5V-CT94-0399 from the European Community
Impaired lung fibrinolytic activity is a manifestation associated with acute and chronic inflammatory lung diseases. Reduced fibrinolytic activity has been found in bronchoalveolar lavage (BAL) fluid of patients with adult respiratory distress syndrome [1,2], sarcoidosis [3] and idiopathic pulmonary fibrosis (IPF) [3, 4]. Persisting matrixbound fibrin observed in these interstitial lung disorders, and conceivably resulting from impaired fibrinolytic activity, is thought to initiate the formation of the fibrotic tissue through enhanced fibroblast cell adhesion/proliferation and subsequent collagen deposition [5, 6]. Of possible relevance to this repair process is the plasminogen activating system, which may limit fibrosis by dismantling the fibrin and pro-collagen scaffolds. In the alveolar space, the major plasminogen activator (PA) responsible for this action was identified as urokinase (uPA) [1, 2]. Inappropriate control of uPA activity either by altered expression of the protein or altered expression of its inhibitors (PAIs) is, therefore, of potential relevance in interstitial lung diseases. We have previously demonstrated an upregulation of uPA in the lung compartment in response to toxic particulate materials [7].

Among the specific regulating factors of uPA activity, two distinct protease inhibitors belonging to the serpins family have been identified $[8,9]$. The plasminogen acti- vator inhibitor-1 (PAI-1), a product of endothelial [10] and epithelial cells [11], is usually regarded as the major inhibitor of PAs in plasma and the alveolar space, respectively. While PAI-1 is synthesized in an active form, it is rapidly converted in solution into a latent inactive variant [10]. PAI-1 is, however, stabilized in its active configuration by interaction with several extracellular matrix proteins such as vitronectin [12] and fibronectin [13]. It has been suggested that extracellularly deposited PAI-1 functions to preserve the integrity of connective tissue by limiting UPA-mediated proteolysis.

Plasminogen activator inhibitor-2 (PAI-2), reported in placenta, keratinocytes and endothelial cells is, however, mainly produced by monocytes and macrophage cells [14, 15]. Like other serpins, PAI-2 inhibits uPA by forming enzymatically inactive 1:1 protease-inhibitor complexes and appears to be more efficient than PAI-1 in inhibiting UPA, but does not react with pro-uPA. A single messenger ribonucleic acid (mRNA) encodes for two forms of PAI-2: a cytosolic nonglycosylated form and a secreted N-glycosylated form [16]. As neither PAs nor enzymes with comparable specificity have been identified in the cytosol, intracellular PAI-2 was suggested to represent an abundant store of inhibitors available for controlled or uncontrolled release. While the available evidence does not 
allow a complete understanding of the role of PAI-2, it is, however, reasonable to speculate on its involvement in the control of uPA-mediated pericellular proteolysis. The contribution of PAI-2 to the prevention of lung cell metastasis supports this view [17]. Increased PAI-2 production was also suggested as a marker of cellular differentiation of monocytes [18] and keratinocytes [19].

The implication of PAI-1 and PAI-2 in particle-induced lung diseases remains largely unknown. Therefore, we have examined in an experimental murine model whether alterations of the production of PAIs in the lung are induced in response to inorganic particles. The time course of changes in soluble PAIs activity was characterized in BAL fluid after a single intratracheal instillation of crystalline silica. Changes in PAIs gene expression were monitored in BAL cell fractions and lung tissue over a period of 30 days after treatment. For this purpose, we have developed a new semi-quantitative polymerase chain reaction (PCR) method for the study of murine PAI-1 and PAI-2 mRNA expression.

\section{Materials and methods}

\section{Reagents}

Crystalline silica (Dörentrup Quartz, ground product no. 12 (DQ12), median particle size: $2.2 \mu \mathrm{m}$ ) was a kind gift of L. Armbruster (Essen, Germany). Monoclonal antibody directed against murine PAI-1 as well as murine purified PAI-1 protein were kindly provided by P. Declerck (KUL, Leuven, Belgium). Fibrinogen fragments were obtained from Boehringer (Mannheim, Germany). Human plasminogen and S2251 (Valine-Leucine-Lysinepara-nitroanilide plasmin substrate) were purchased from Chromogenix (Mölndal, Sweden). Human urokinase was from Calbiochem (La Jolla, USA). Tris-hydroxymethylaminomethane (Tris), bovine serum albumin (BSA), glycine and lipopolysaccharide (LPS) from Escherichia coli were from Sigma (St Louis, USA), 1,2-phenylenediamine was from Flucka (Buch, Switzerland) and pentobarbital was from Siegfried Chemie (Brussels, Belgium). Trizol reagent (lot number: 1000030), Superscript II ribonuclease (RNAse) H- (lot number: JC3405) were from Gibco BRL (Gaithersburg MD, USA). Taq deoxyribonucleic acid (DNA) polymerase and deoxynucleoside triphosphate (dNTPs) were from Perkin Elmer (Branchburg, New Jersey, USA).

\section{Animals}

Adult female NMRI mice (8 weeks, 20-25 g) purchased from Iffa Credo (Brussels, Belgium) were housed in an air conditioned room $\left(22^{\circ} \mathrm{C}\right.$, relative humidity $50 \pm$ $10 \%$ ) with a $12 \mathrm{~h}$ light/dark cycle and fed on a conventional laboratory diet.

\section{In vivo treatment}

The animals were anaesthetized by i.p. injection of pentobarbital $\left(80 \mathrm{mg} \cdot \mathrm{kg}\right.$ body weight $\left.{ }^{-1}\right)$. The trachea was exposed using a sterile technique and 5 mg DQ12 suspended in $100 \mu$ sterile saline solution was slowly instilled into the trachea lumen. This dose of silica was demonstrated in preliminary experiments to cause a fibrotic response within 1 month [7]. Controls were treated with an equivalent volume of saline. At selected time intervals after treatment $(1,3,5,15$ and 30 days), animals were killed by pentobarbital overdose. Lung tissue (two mice per group) and alveolar macrophages (5-10 mice per group) were harvested. Alveolar macrophages were recovered by BAL using sterile saline, as previously described [20]. The BAL fluid sample were centrifuged $(1,200 \mathrm{~g}, 10 \mathrm{~min}$, $4^{\circ} \mathrm{C}$ ). The cell-free supernatants of the first lavage fraction were used for biochemical measurements of PAIs and the cell pellets obtained from 4-5 animals were pooled and used for mRNA extraction. The total number of live cells recovered by BAL was determined by the trypan blue exclusion method and differential cell counts were performed on cytocentrifuge preparations stained with Diff Quick (Dade NV/SA, Brussels, Belgium).

In a separate group of mice, LPS diluted in sterile saline was injected intravenously at a dose of $100 \mu \mathrm{g}$ per mouse. Lung tissue from LPS-stimulated mice was recovered $2 \mathrm{~h}$ after treatment and used as positive control for PAI-1 and PAI-2 mRNA expression [21, 22].

\section{Ribonucleic acid (RNA) extraction and reverse transcription}

DNA and total RNA were purified from BAL cells (1.2-2 $\times 10^{6}$ cells) and lung tissue according to the procedure supplied with the Trizol reagent. Both in control and silica-treated mice, RNA extraction was performed on the totality of cells recovered by BAL. The RNA pellet was washed with $75 \%$ ethanol, air-dried and dissolved in diethyl pyrocarbonate-treated water. An equivalent quantity of total RNA was used to compare PAI mRNA levels in controls and silica-treated mice. Single-stranded complementary deoxyribonucleic acid (cDNA) was synthesized from $2.5 \mu \mathrm{g}$ of the RNA preparation in a final volume of $50 \mu \mathrm{L}$ using random hexamers and Moloney murine leukaemia virus reverse transcriptase as directed by the manufacturer.

\section{Amplification of specific cDNA by polymerase chain reaction}

The primers (table 1) were selected within mouse PAI-1, PAI- 2 and $\beta$-actin sequences. A total of $2.25 \mu \mathrm{L}$ of the reverse transcribed product or $25 \mathrm{ng}$ of mouse genomic DNA were used in the PCR. Amplifications were as follow: $10 \mathrm{mM}$ Tris-HCl buffer ( $\mathrm{pH} 8.3$ ), with 1.2 $\mathrm{mM}$ (PAI-1) or $1.5 \mathrm{mM}$ (PAI-2, $\beta$-actin) $\mathrm{MgCl}_{2}, 0.2 \mathrm{mM}$ of each dNTPs, 5 pmol of each 5' and 3' specific primers in a final volume of $25 \mu \mathrm{L}$. The exponential phase of each amplification was determined by carrying out reactions with increasing numbers of cycles (16-36) and using three concentrations of LPS-stimulated lung cDNA. The reactions were carried out in a DNA thermal cycler (Perkin Elmer, Norwalk, Connecticut, USA) using Taq DNA polymerase. Each amplification cycle consisted of denaturing at $94^{\circ} \mathrm{C}$ for $30 \mathrm{~s}$, annealing primers to target 
Table 1. - Oligonucleotides used in the reverse transcriptase polymerase chain reaction (RT-PCR)

\begin{tabular}{lclcc}
\hline \multirow{2}{*}{$\begin{array}{l}\text { Murine } \\
\text { transcripts }\end{array}$} & Primer & \multicolumn{2}{c}{ Sequence (5'-3') } & \multicolumn{2}{c}{ Location of primer in cDNA sequence according to EMBL data bank } \\
\cline { 3 - 5 } & & & EMBL accession & Nucleotides \\
\hline$\beta$-actin & Forwards & ATGGATGACGATATCGCTGC & X03672 & $81-100$ \\
& Reverse & GCTGGAAGGTGGACAGTGAG & X03672 & $1131-1150$ \\
PAI-1 & Forwards & GTGGTCTTCTCTCCCTATG & M33960 & $294-313$ \\
& Reverse & CTCTGAGAAGTCCACCTGT & M33960 & $565-584$ \\
PAI-2 & Forwards & ACAGCAGATGGCCAAAGTGCT & X16490 & $164-184$ \\
& Reverse & AGAACCTTCGGGTAGCAGGTT & X16490 & $558-579$ \\
\hline
\end{tabular}

EMBL: European Molecular Biology Laboratory; cDNA: complementary deoxyribonucleic acid; PAI: plasminogen activator inhibitor.

sequences at $60^{\circ} \mathrm{C}(\mathrm{PAI}-1, \mathrm{PAI}-2)$ or $55^{\circ} \mathrm{C}(\beta$-actin) for 30 $\mathrm{s}$, and primer extension at $72^{\circ} \mathrm{C}$ for $1.30 \mathrm{~min}$. Negative controls (reverse transcription omitted) were included to assess DNA contamination of the samples, and amplification of the PCR mixture without cDNA was included to assess contamination at later stages. Fifteen microlitres (PAIs) or $25 \mu \mathrm{L}$ ( $\beta$-actin) of the PCR products were resolved by $2 \%$ agarose gel electrophoresis stained with ethidium bromide. Relative amounts of specific mRNA were quantified by densitometric 2-dimensions analysis (peak area) of the photographic polaroid using image analysis software (MCID software; Imaging Research, St Catharines, Ontario, Canada). To assess the level of $\beta$ actin as well as PAI gene expression, the mRNA content of each sample was determined by comparison to a reference sample (LPS- stimulated lung mRNA). Calibration curves, consisting of serial dilutions of the reference sample (reverse transcribed at the same time as the target samples), were performed and run in parallel with the studied samples. Each calibration curve was generated by plotting the amount of amplified product issued from the reference sample as a function of the dilution of the starting cDNA. To allow a reliable mRNA measurement, three PCR amplifications per specific gene were performed for each cDNA sample. Using this procedure, we obtained an interassay variability coefficient of 5-10\%. In the presence of higher transcript levels, samples were serially diluted and reamplified. PAI mRNA levels were expressed as a ratio to $\beta$-actin mRNA in order to correct for any variation in RNA content or cDNA synthesis in the different samples.

\section{Nucleotide sequencing}

The authenticity of the PCR fragment was verified by nucleotide sequencing of LPS-stimulated material. Purified PCR fragments (Quiaquick purification kit, Quiagen, Hilden, Germany) were cycle sequenced using the Dyedideoxy chain termination method (Taq Dye Deoxy ${ }^{\mathrm{TM}}$ Terminator Cycle sequencing kit; Applied Biosystem, Foster City, California, USA). Nucleotide sequences were determined using an automated DNA sequencer (373A; Applied Biosystem).

\section{Biochemical measurement of PAIs}

The PAI activity was assayed in BAL fluid by monitoring the ability of PAI-1 and PAI-2 to inactivate human urokinase. The residual urokinase activity was measured as previously described by LePRINCE et al. [23]. The quantifi- cation method used is indirect: urokinase converts exogenous plasminogen into plasmin and the subsequent plasmin-dependent hydrolysis of a synthetic substrate (S2251) is then monitored. Briefly, $50 \mu \mathrm{L}$ of BAL fluid was incubated during $15 \mathrm{~min}$ at room temperature in $0.1 \mathrm{M}$ Tris/ $0.1 \mathrm{M}$ glycine/0.5\% BSA buffer $(\mathrm{pH} 8.5)$ in the presence of human urokinase (3 IU). After this incubation period, S2251 substrate $(0.7 \mathrm{mM})$, fibrinogen fragments $(530 \mathrm{pg})$ and human plasminogen $(0.14 \mathrm{mM})$ were added to the test tube in a final volume of $250 \mu \mathrm{L}$. The measurements were performed in triplicate in 96-well plates incubated at $37^{\circ} \mathrm{C}$. Wells in which plasminogen was omitted were assayed simultaneously for each sample. The formation of p-nitroaniline from the hydrolysis of S2251 was followed spectrophotometrically at $405 \mathrm{~nm}$ (Twinreader Titertek, Flow Laboratories, Helsinki, Finland) every 15 min over a period of $10 \mathrm{~h}$. The difference in optical density between plasminogen-containing and plasminogen-free wells was plotted against the square of the incubation time and the slope of the regression line calculated. The determination of remaining urokinase activity in the sample was calculated as described by SCHNYDER et al. [24]. PAI activity was expressed as the percentage of urokinase inhibition in the sample.

Determination of murine PAI-1 protein in BAL fluid samples was performed with a two-site non-competitive enzyme-linked immunosorbent assay (ELISA) as described by DECLERCK et al. [25] using a conventional peroxidase detection method with 1,2-phenylenediamine as substrate. The detection limit was $1.2 \mathrm{ng} \cdot \mathrm{mL}^{-1}$. No ELISA was available for murine PAI-2.

\section{Others analyses}

Total lung hydroxyproline content (five mice per group) was analyzed by high pressure liquid chromatography (HPLC) technique as previously described [26]. BAL fluid total protein content was assessed spectrophotometrically using a commercial kit (Systemes Technicon, Doumon, France). BAL fluid lactate dehydrogenase activity (LDH) was assessed spectrophotometrically by monitoring the reduction of nicotinamide adenine dinucleotide $\left(\mathrm{NAD}^{+}\right)$at $340 \mathrm{~nm}$ in the presence of lactate.

\section{Statistical analysis}

Data are expressed as mean \pm SEM. Comparison between groups was assessed using analysis of variance (ANOVA) and the Student-Newman-Keul test. Statistical significance was defined as pð0.05. 


\section{Results}

Silica-induced lung inflammatory and fibrotic lung responses

The alveolitis response was monitored by measuring LDH activity and total protein content in BAL fluid (table 2 ). Whatever the time point considered, LDH activity and protein content in BAL fluid remained constant in control mice. In response to silica, we noted a rapid and significant increase in BAL fluid LDH activity and total protein content, with a maximal increase at day 3 . One month after silica treatment, a sustained and significant increase in both parameters was still noted compared to controls.

BAL fluid cellular patterns are presented in table 2 . The BAL cell population of control mice showed a constant cell number and was almost exclusively composed of alveolar macrophages, except at day 1 where $3 \%$ of neutrophils were detected. In response to silica treatment, we noted a rapid and persisting significant increase in the total cell number, with a maximum at day 3 . The inflammatory response induced by silica administration was characterized by a rapid and significant recruitment of alveolar macrophages and neutrophils. Maximal numbers of both alveolar macrophages and neutrophils were noted at day 3 after silica administration. In percentage terms, however, neutrophils represented $70 \%$ of BAL cell population at day 1 after silica treatment. One month after silica administration, the number of alveolar macrophages returned to control value, while neutrophil influx was still present and represented $15 \%$ of the BAL cell population. No other cell types were identified in BAL inflammatory cells elicited by silica treatment.

One month after silica treatment, histological examination of lung tissue showed well-established fibrosis with positive Masson's trichrome staining (not shown) associated with a weak, but nonsignificant increase in total lung hydroxyproline content $\left(147 \pm 13 \mu \mathrm{g} \cdot\right.$ lung $^{-1}$ in silica versus $104 \pm 13 \mu \mathrm{g} \cdot \mathrm{lung}^{-1}$ in controls). A significant increase in total lung hydroxyproline content was observed at 2 months (392 $\pm 19 \mu \mathrm{g} \cdot$ lung $^{-1}$ in silica versus $216 \pm 7 \mu \mathrm{g} \cdot$ lung $^{-1}$ in controls) and maintained up to 4 months $\left(481 \pm 14 \mu \mathrm{g} \cdot\right.$ lung $^{-1}$ in silica versus $286 \pm 28 \mu \mathrm{g} \cdot$ lung $^{-1}$ in controls) after silica treatment.

\section{Changes in BAL fluid PAI activity and proteins}

The soluble PAI activity was determined in BAL fluid obtained from control and silica-treated mice over a period of 30 days (fig. 1). PAI activity remained almost constant over 30 days in control animals. The administration of $5 \mathrm{mg}$ silica produced a rapid (day 1) and significant increase in soluble PAI activity. With time, soluble PAI activity declined progressively to return to control value at day 15. One month after silica treatment, no soluble PAI activity was detected.

Changes in PAI-1 levels (fig. 2) have also been studied up to day 30. Whatever the time point considered, PAI-1 antigen was never detected in control BAL fluid. A significant increase in BAL fluid PAI-1 antigen was observed during the acute phase of silica-induced lung injury (up to day 5). As observed for the PAI activity measurements, maximal PAI-1 levels occurred at day 1 and decreased progressively with time.

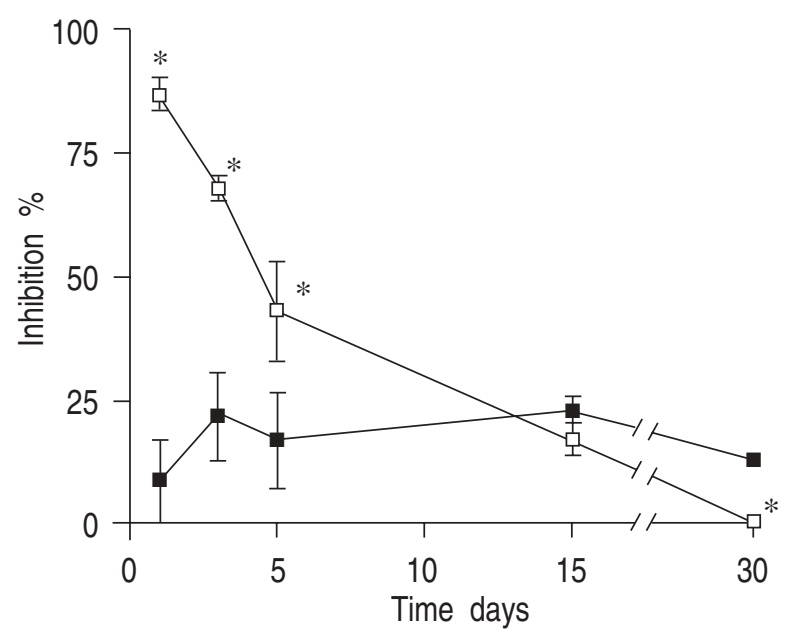

Fig. 1. - Time course of soluble plasminogen activator inhibitor (PAI) activity in bronchoalveolar lavage fluid (BALF) in response to a single intratracheal administration of crystalline silica $\left(5 \mathrm{mg} \cdot \mathrm{mouse}^{-1}\right)$. Values represent the mean \pm SEM of 4-6 mice. *: pð0.01.

Table 2. - Kinetics of the lung inflammatory changes in bronchoalveolar lavage in response to silica (5 mg.mouse-1)

\begin{tabular}{|c|c|c|c|c|c|}
\hline \multirow{2}{*}{ Parameter } & \multicolumn{5}{|c|}{ Time days } \\
\hline & 1 & 3 & 5 & 15 & 30 \\
\hline \multicolumn{6}{|c|}{$\overline{\text { LDH IU } \cdot \mathbf{L}^{-1}}$} \\
\hline Controls & $32 \pm 2$ & $25 \pm 3$ & $27 \pm 3$ & $26 \pm 3$ & $30 \pm 1$ \\
\hline Silica & $116 \pm 4 *$ & $224 \pm 17 *$ & $154 \pm 13 *$ & $51 \pm 3 *$ & $58 \pm 4 *$ \\
\hline \multicolumn{6}{|c|}{ Total proteins $\mu \mathrm{g} \cdot \mathrm{mL}^{-1}$} \\
\hline Controls & $92 \pm 17$ & $75 \pm 9$ & $82 \pm 7$ & $84 \pm 6$ & $80 \pm 1$ \\
\hline Silica & $831 \pm 52 *$ & $1530 \pm 151 *$ & $673 \pm 82 *$ & $151 \pm 16^{*}$ & $139 \pm 17 *$ \\
\hline \multicolumn{6}{|c|}{ Total cell number $n \times 10^{3}$} \\
\hline Controls & $311 \pm 55$ & $354 \pm 65$ & $362 \pm 62$ & $214 \pm 41$ & $226 \pm 11$ \\
\hline Silica & $635 \pm 51 *$ & $1732 \pm 290^{*}$ & $924 \pm 104 *$ & $465 \pm 44^{*}$ & $380 \pm 19 *$ \\
\hline \multicolumn{6}{|c|}{ Macrophage $\mathrm{n} \times 10^{3}$} \\
\hline Control & $330 \pm 48$ & $357 \pm 46$ & $329 \pm 38$ & $214 \pm 41$ & $278 \pm 64$ \\
\hline Silica & $184 \pm 30 *$ & $894 \pm 221 *$ & $722 \pm 96 *$ & $432 \pm 42 *$ & $321 \pm 18$ \\
\hline \multicolumn{6}{|c|}{ Neutrophils $n \times 10^{3}$} \\
\hline Controls & $10 \pm 5$ & $1.4 \pm 0.7$ & $0.5 \pm 0.3$ & $0 \pm 0$ & $1.5 \pm 0.9$ \\
\hline Silica & $467 \pm 54 *$ & $852 \pm 160 *$ & $258 \pm 49 *$ & $41 \pm 18^{*}$ & $57 \pm 9 *$ \\
\hline
\end{tabular}

Data represent arithmetic mean \pm SEM from $4-8$ and 6-10 mice for controls and silica treatment, respectively. *: $\mathrm{p}<0.05$ versus controls. 


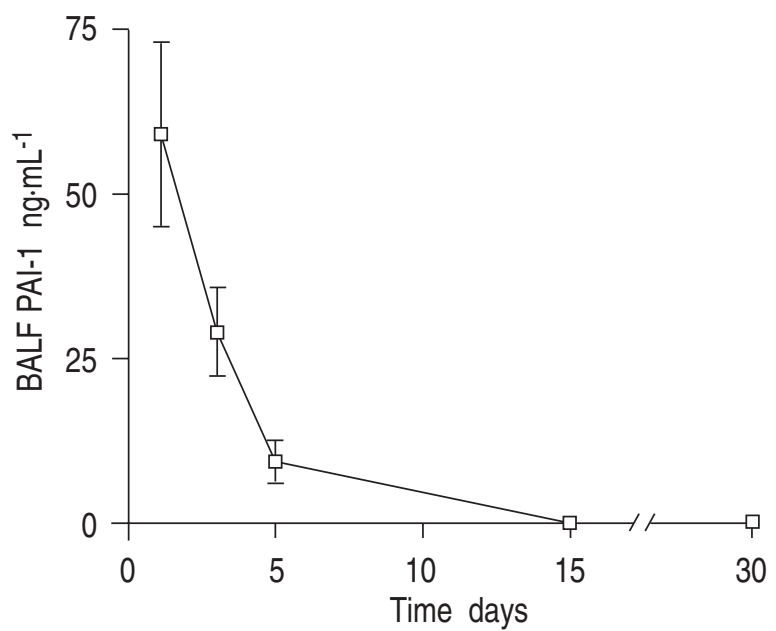

Fig. 2. - Enzyme-linked immunosorbent assay (ELISA) measurements of plasminogen activator inhibitor-1 (PAI-1) in bronchoalveolar lavage fluid (BALF) during the course of lung injury induced by a single intratracheal administration of crystalline silica $\left(5 \mathrm{mg} \cdot\right.$ mouse- $\left.^{-1}\right)$. Values represent the mean \pm SEM of 4-6 mice. PAI-1 antigen was never detected in the controls.

\section{Expression of PAI-1 and PAI-2 mRNAs}

PCR characterization. LPS-stimulated lung cDNA yield${ }^{2}$ ed a single PCR product of the expected size of 291 and 415 base pairs for PAI-1 and PAI-2 mRNAs, respectively (fig. 3). The specificity of the amplified products was confirmed by sequencing. No variation was found between the published sequences of mouse cDNAs [16, 27] and that of the PCR products. Mouse genomic DNA samples assessed by the same PCR procedures gave products larger than the cDNA amplicons (fig. 3). Possible contamination of RNA preparation by genomic DNA could, therefore, be easily excluded.

The exponential phase of each cDNA amplification was determined by carrying out the reaction for 16-36 cycles using at least three concentrations of LPS-stimulated lung cDNA. The PAI-1 fragment became visible in ethidium

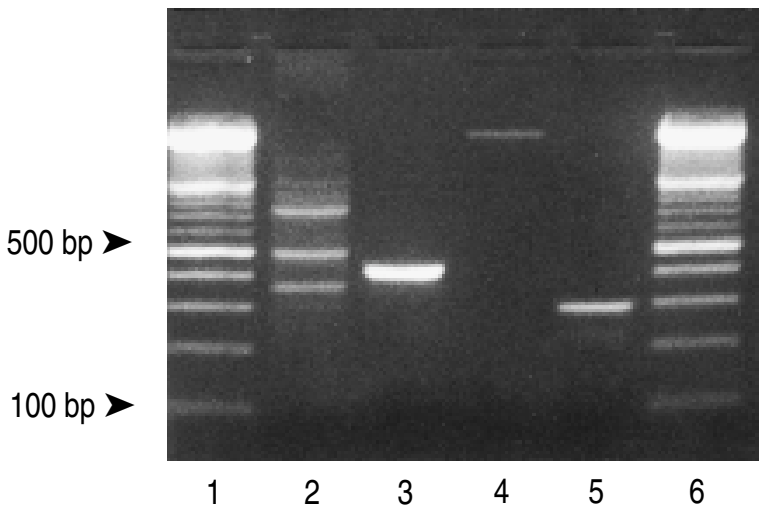

Fig. 3. - Identification of murine plasminogen activator inhibitor (PAI) messenger ribonucleic acid (mRNA). Complementary deoxyribonucleic acid (cDNA) from lipoploysaccaride (LPS)-stimulated lung analysed by the polymerase chain reaction (PCR) procedure, as described in Materials and methods, gave the expected amplification product for PAI-1 (291 base pairs (bp), lane 4) and for PAI-1 (495 bp, lane 3). The amplification products obtained from $25 \mathrm{ng}$ of genomic DNA are visualized in lane 5 for PAI- 1 and in lane 2 for PAI-2. The values represent the number of base pairs for the DNA ladder (lanes 1 and 6). a)
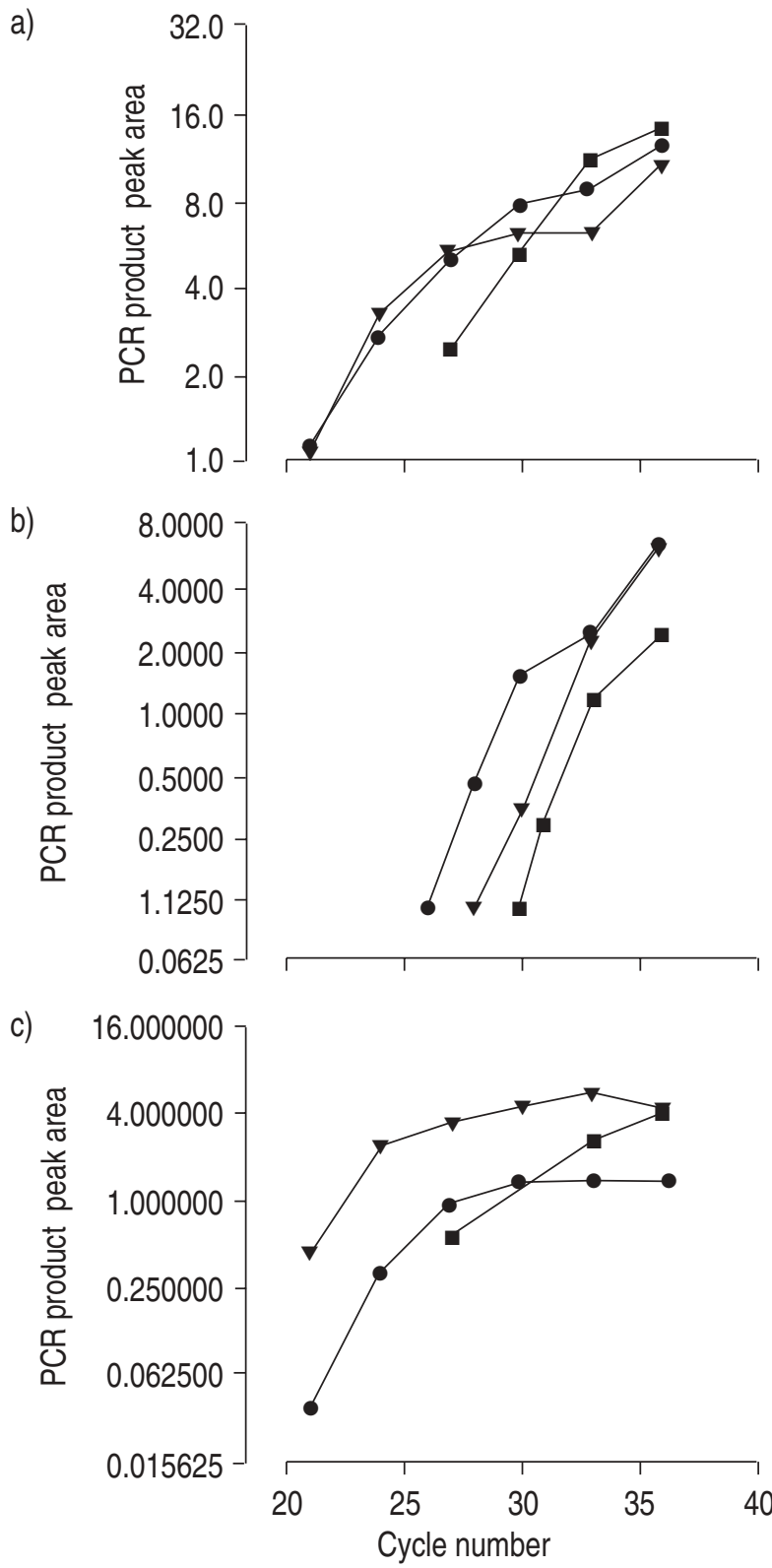

Fig. 4. - Kinetic analysis of the PCR amplification of LPS-stimulated lung cDNA. Amplification of: a) PAI-1; b) PAI-2; or c) $\beta$-actin fragments was started with undiluted $(\boldsymbol{\nabla}), 10$ times $(\bullet)$ or 100 times $(\boldsymbol{\square})$ diluted reverse transcriptase (RT) products. Yield of PCR product is given in a logarithmic scale. For definition of abbreviations, see legend to figure 3 .

bromide stain at reaction cycle 21 of PCR (fig. 4a) and PAI-2 fragment at reaction cycle 26 (fig. 4b). A total of 27 and 33 amplification cycles were selected for PAI-1 and PAI-2, respectively, in order to achieve amplification in the exponential range of the PCR process. For $\beta$-actin the plateau phase was quickly reached (fig. 4c) and a total of 25 amplification cycles was selected. Among the different concentrations of starting material tested, a 10 fold dilution of the reverse transcriptase (RT) product was retained since better amplifications of PAI mRNAs were observed in this range of template concentration.

The normalization of the PCR product yield was achieved by using $\beta$-actin mRNA as an internal control. To verify whether $\beta$-actin was expressed in a constitutive 

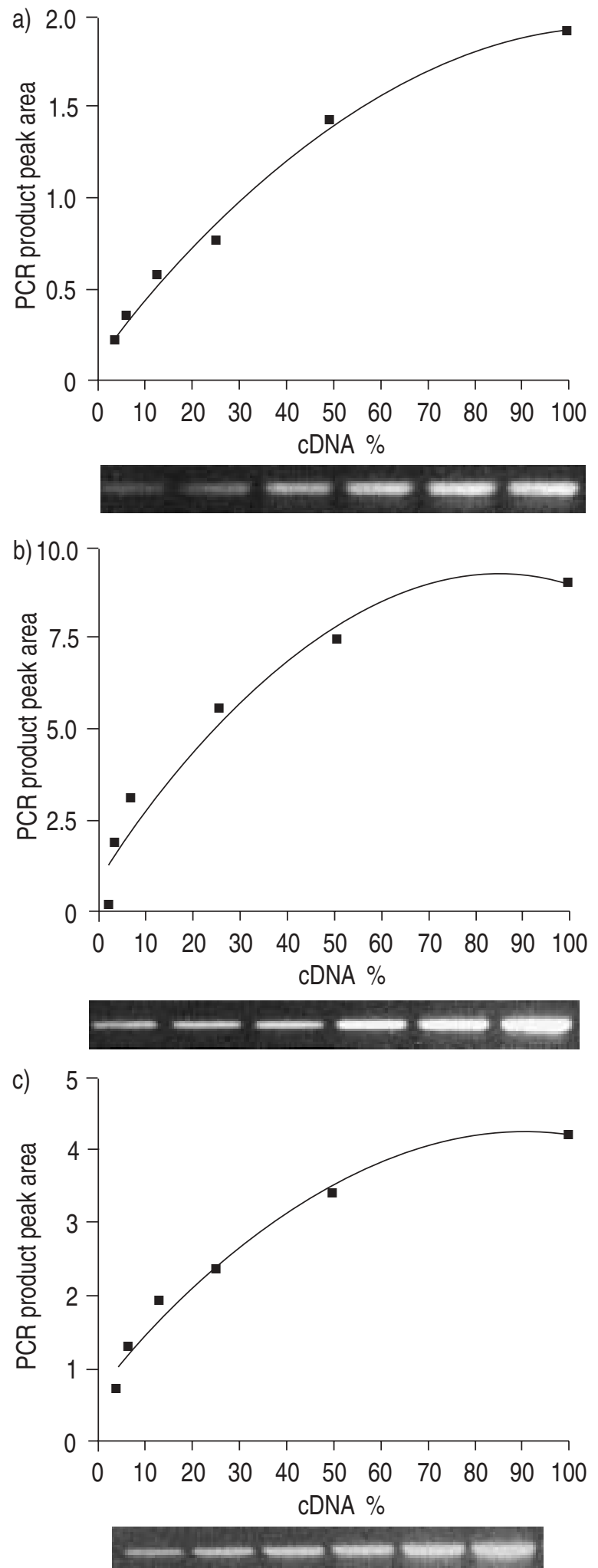

Fig. 5. - Calibration curves for reverse transcriptase polymerase chain reaction (RT-PCR) semi-quantitation of: a) PAI-1 ; b) PAI-2; and c) $\beta$ actin transcripts. The curves were established from serial dilutions (1:10 to $1: 320$ ) of LPS-stimulated lung cDNA obtained from $2.5 \mu \mathrm{g}$ (PAIs) or $5 \mathrm{mg}$ (actin) of total RNA. The yield of PCR product measured by two dimensional analysis was plotted against the percentage of positive control engaged in the PCR. The $100 \%$ level corresponds to 1:10 dilution. For definitions of abbreviations, see legend to figure 3.
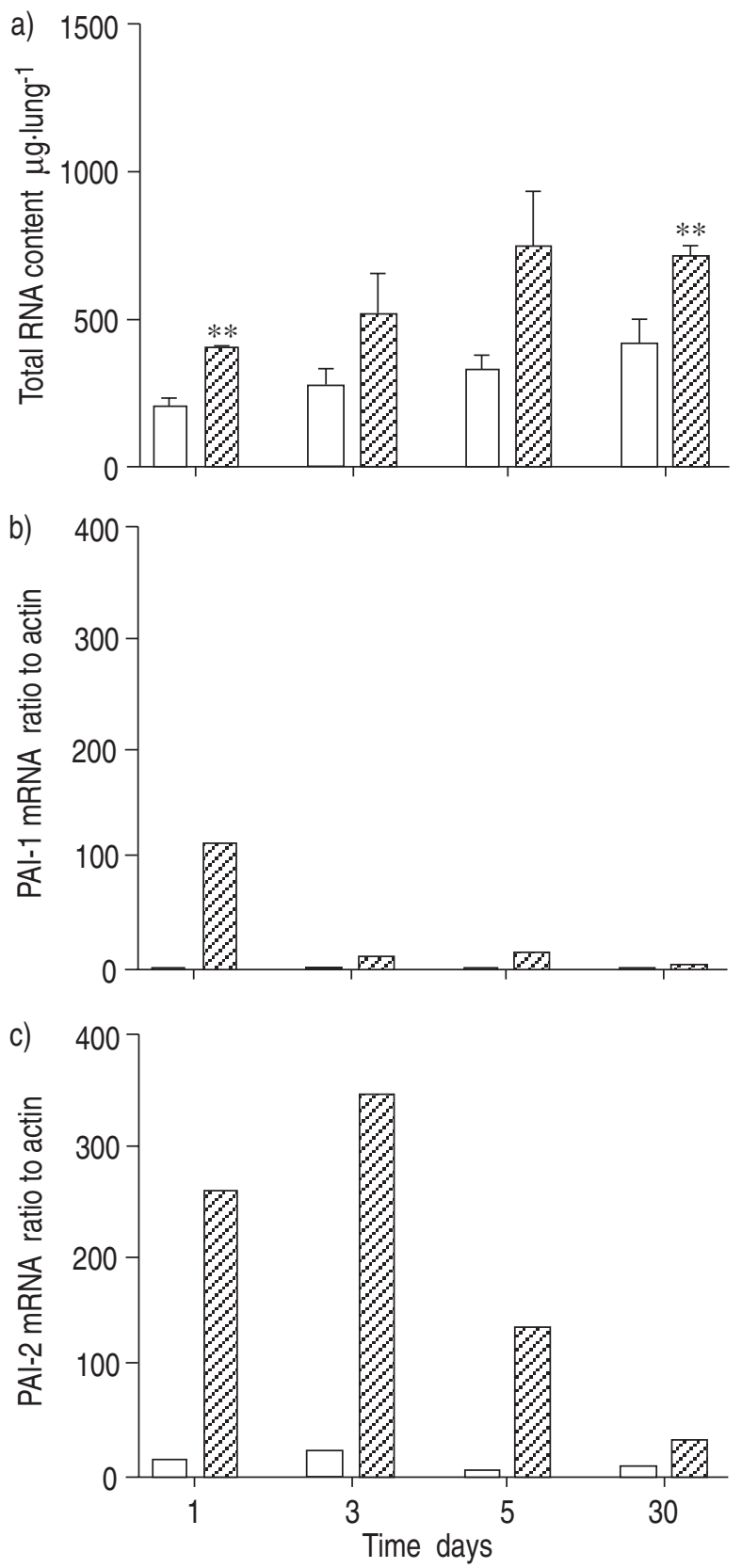

d)

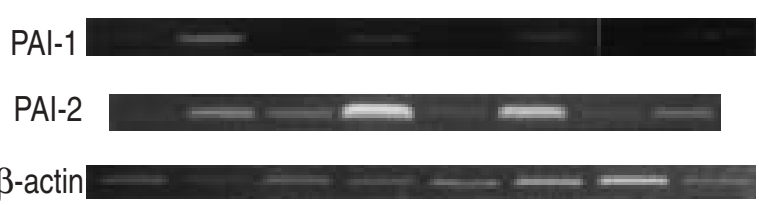

Fig. 6. - Time course of the induction of PAI mRNA levels in lung tissue following a single intratracheal administration of crystalline silica $\left(5 \mathrm{mg} \cdot\right.$ mouse $\left.^{-1}\right)$. Total lung RNA content at each time points is shown in panel a. Bars represent the mean \pm SEM of 2-3 animals. The relative change in PAI-1 (panel b) and PAI-2 (panel c) mRNA observed in response to silica treatment were determined from calibration curves shown in figure 5. Data represent means of 3-4 PCR amplifications performed on 1:10 diluted cDNA and are expressed as a ratio to actin (see Methods). Panel d represents gel photographs of representative PAI-1 (291 bp), PAI-2 (405 bp) and $\beta$-actin (1069 bp) PCR products resolved by $2 \%$ agarose gel electrophoresis stained with ethidium bromide. No signal for PAI-1 was ever detected in lungs from control mice. $\quad$ control; EZilica-treated. **: $\mathrm{p}<0.01$ versus controls. For definitions of abbreviations, see legend to figure 3 . 
manner, we tested the effect of LPS, known to induce a variety of proteins, on the lung expression of $\beta$-actin mRNA. As expected, no modification of the $\beta$-actin mRNA level could be detected (data not shown). Arbitrary values (percentage of reference sample) for PAI-1, PAI-2 and $\beta$-actin mRNA content of each sample were determined from calibration curves (fig. 5). The best fit for the experimental values was obtained with nonlinear regression (second order polynomial). The correlation values $\left(\mathrm{r}^{2}\right)$ for PAI-1, PAI- 2 and $\beta$-actin calibration curves shown in figure 5 were $0.994,0.959$ and 0.973 , respectively. To allow standardization of the calibration procedure, we only considered $\mathrm{r}^{2} \mathrm{~S} 0.95$ as an acceptable value.
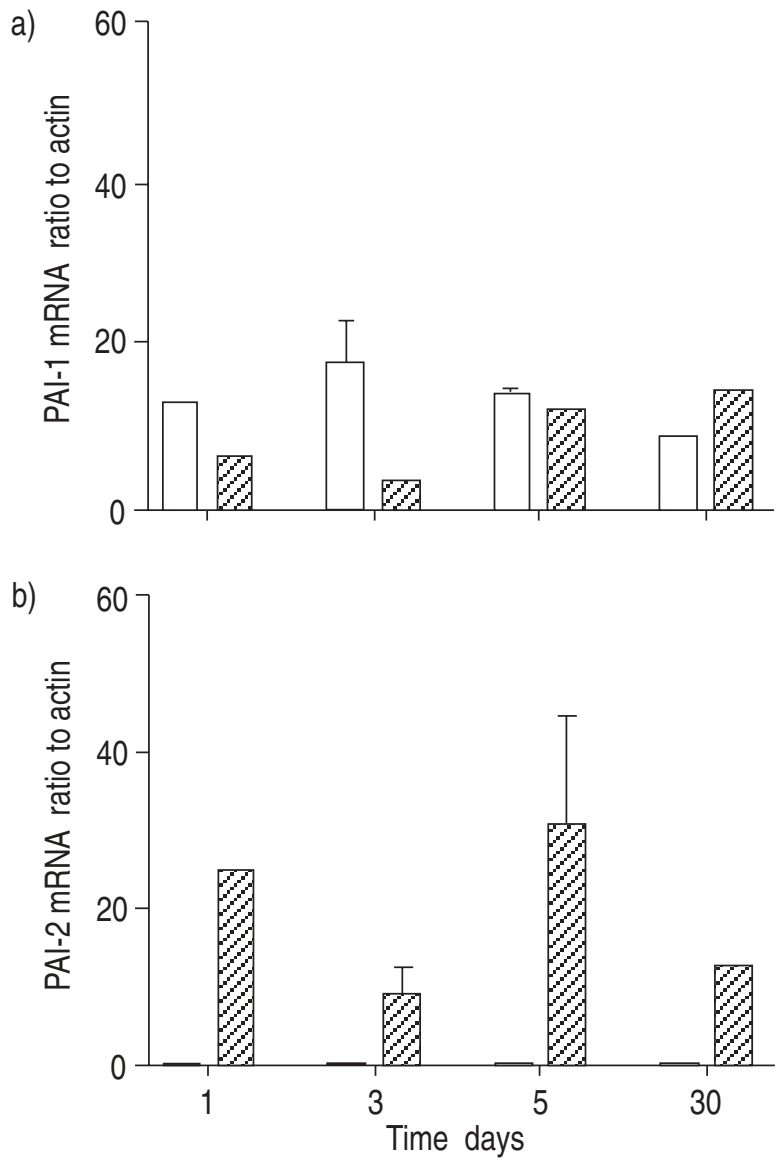

C)

PAl-1

PAl-2

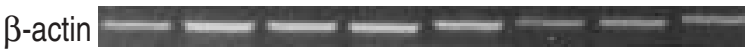

Fig. 7. - Changes in PAI mRNAs levels in bronchoalveolar lavage (BAL) inflammatory cells elicited by a single intratracheal administration of crystalline silica (5 mg.mouse- ${ }^{-1}$. The relative changes in: a) PAI-1; and b) PAI-2 mRNA observed in response to silica treatment were determined from calibration curves shown in figure 5. Data represent the mean of 3-4 PCR amplifications performed on 1:10 diluted cDNA and are expressed as a ratio to actin (see Methods). Panel c represents gel photographs of representative PAI-1 (291 bp), PAI-2 (405 bp) and $\beta$-actin $(1069 \mathrm{bp})$ PCR products resolved by $2 \%$ agarose gel electrophoresis stained with ethidium bromide. No signal for PAI- 2 was ever detected in alveolar macrophages from control mice. $\square$ : control; $Z Z$ : silicatreated. For definitions of abbreviations see legend to figure 3.
Induction of PAI-1 and PAI-2 mRNAs by silica

Total lung RNA was examined for the presence of either PAI-1 or PAI-2 mRNA by RT-PCR up to day 30 after silica treatment. Compared to controls' we observed an increase in total RNA content in the silica groups, whatever the time point considered (fig. 6a). More specifically, increase of PAI-1 (fig. 6b) and PAI-2 (fig. 6c) mRNA were noted. Under basal conditions, PAI-1 mRNA was not detected in lung tissue. After silica treatment, PAI-1 mRNA was easily detectable. The strongest PAI-1 mRNA upregulation was noted at day 1 . The level of PAI-1 mRNA decreased progressively with time but was still maintained higher than in controls at day 30. At the opposite, PAI-2 mRNA was detected in lung tissue of controls. After silica treatment, PAI-2 mRNA levels increased rapidly and showed maximal upregulation at day 3 (14 fold increase compared to controls). One month after silica treatment, we still noted a fourfold increase of PAI-2 mRNA compared to the control group. Similar levels of $\beta$-actin mRNA were found in the control and silica lung cDNA samples (fig. 6d).

Total RNA from BAL cells from controls and silica-treated mice was also examined for the presence of PAI mRNA. Figures $7 \mathrm{a}$ and $\mathrm{b}$ depict changes in PAI-1 and PAI-2 mRNA, respectively in inflammatory cells. Whatever the time point considered, PAI-1 mRNA showed similar levels in control macrophages. Compared to the control group, silica induced only a slight downregulation in cellular PAI-1 mRNA levels at day 1 and 3. Not detected in control macrophages, PAI-2 mRNA was strongly upregulated during the course of the alveolitis induced by silica. One month after silica treatment, upregulation of PAI-2 mRNA was still detectable. Identical levels of $\beta$-actin mRNA were observed between the control and silicarecruited inflammatory cell cDNA samples (fig. 7c). Identical results were found in two separate determinations at days 3 and 5 .

\section{Discussion}

A balanced regulation of fibrinolysis is critical for the maintenance of normal alveolar structure, and a local disruption of the PA/PAI system may lead to alveolar accumulation and persistence of fibrin. We previously demonstrated a marked upregulation of lung urokinase during the course of both alveolitis and fibrosis induced by silica particles in the mouse [7]. In the present study we describe a concomitant increase in both BAL fluid PAI activity and PAI-1 protein in the same model. Upregulation of lung PAI- 1 activity and gene expression has also been suggested to contribute to the development of interstitial lung disease associated with adult respiratory distress syndrome [4] and bleomycin-induced lung injury [28]. The potential involvement of PAI-2 in the lung inflammatory response was suggested by the observation that tumour necrosis factor (TNF)- $\alpha$, a profibrotic cytokine expressed during lung fibrogenesis [29], is a potent inducer of PAI-2 transcription [30]. Furthermore, both PAI-1 and PAI-2 were found to be upregulated by interleukin (IL)-1, transforming growth factor (TGF) $\beta$, LPS and TNF- $\alpha$ in several cell types [21, 22, 30-32] suggesting an important role of these inhibitors during 
inflammation. In an attempt to clarify the involvement of both PAIs in interstitial lung disease, we characterized the time course of lung PAI-1 and PAI-2 changes accompanying the lung reaction induced by crystalline silica in a murine model. Silica-induced lung injury is an established murine model of pulmonary fibrosis $[7,33]$. A single dose of the highly toxic DQ12 silica $[7,34,35]$ induced a severe and persistent alveolitis characterized by significant increases in lactate dehydrogenase (LDH) and total protein content in BAL fluid. Concomitantly, a rapid and significant recruitment of monocytes/macrophages and neutrophils was also noted in response to silica (table 2). Subsequent development of lung fibrosis was evidenced by significant increase of total lung hydroxyproline content.

Appreciable levels of soluble PAI activity were detected in BAL fluid of control animals. The nature of this PAI could, however, not be identified with certainty. In control animals, no PAI-1 was detected at the protein level in BAL fluid and we could not assess the level of PAI2 protein. PAI-1 expressed by resident alveolar macrophages may conceivably represent the most abundant inhibitor in BAL fluid, but the involvement of PAI-2 cannot be excluded since substantial amounts of PAI- 2 mRNA were found in control lung tissue. Whether the cytosolic inhibitor PAI-2 can be released through a post-transcriptional translocation process or whether it is only released under conditions of cell death or apoptosis is not known. Of note, low levels of soluble PAI-2 protein have been found in BAL fluid of healthy human subjects [4].

We previously demonstrated that a single intratracheal administration of silica $\left(5 \mathrm{mg} \cdot \mathrm{mouse}^{-1}\right)$ induced an acute increase in BAL fluid and cell-associated PA activity [7]. Using the same experimental model, we report in the present study a concomitant and marked increase of both BAL fluid PAI activity and PAI-1 protein. Maximal at day 1 , the soluble PAI activity and PAI- 1 protein levels decreased progressively during the course of alveolitis. While changes in soluble BAL fluid PAI-2 level have never been found in several lung fibrotic diseases $[3,4$, 36 , a participation of PAI-2 in the increased BAL fluid PAI activity observed in the mouse in response to silica cannot be excluded. Our mRNA findings support the probable involvement of PAI-2 during silica-induced inflammation, since within the first week following treatment, we observed a significant increase of PAI-2 mRNA in both inflammatory alveolar macrophages and lung tissue. The upregulation of PAI-2 mRNA level might reflect a direct stimulatory effect of silica on the macrophage or, alternatively, the recruitment of peripheral monocytes/ macrophages induced by silica. Several studies on human monocytes have, in particular, described increased PAI-2 mRNA expression in association with cellular differentiation [18]. In addition, although it is generally assumed that neutrophils have a low transcriptional activity, these cells were recently found to present some transcriptional activity for the tissue inhibitor of metalloproteinase (TIMP)-1 [37] and for $92 \mathrm{kDa}$ gelatinase [38], thus suggesting the possible involvement of inflammatory neutrophils in the upregulation of PAI- 2 mRNA levels in BAL cells from silica-treated mice. Our results do not, however, support this possibility. While the number of neutrophils was dramatically increased during the acute inflammatory stage (day 3 ), their relative contribution to the BAL population decreased progressively with time, but this was not accompanied by a reduction of PAI- 2 mRNA levels. PAI-2 mRNA levels remained almost constantly upregulated over the whole observation period in silica-treated mice, paralleling the almost constant recruitment of alveolar macrophages and pointing to this cell type as the most probable source of PAI- 2 in BAL cells. In addition to alveolar macrophages, other lung cell types have previously been found to express PAI-2 antigen [4]. Alveolar epithelial cells and interstitial macrophages might, in com-mon with alveolar macrophages, limit parenchymal pericellular proteolysis and allow the persistence of fibrin scaffolds in the lung parenchyma.

In alveolar macrophages, contrary to PAI-2, increased PAI-1 mRNA expression was never observed after treatment with silica. Macrophages did not, therefore, actively contribute to the increase of soluble PAI-1 activity observed during the course of silica-induced alveolitis. Since a loss of vascular integrity has been reported during silicainduced alveolitis [33], vascular leakage of PAI-1 protein may represent a possible source of increased BAL fluid PAI-1 protein. However, in situ PAI-1 production by other lung parenchymal cell types may also account for early changes in soluble PAI-1. This contribution seems especially relevant during the first week after injury since BAL fluid PAI-1 protein increased concomitantly with lung PAI-1 mRNA. In vitro, alveolar epithelial cells and lung fibroblasts were shown to produce PAI-1 [11, 39]. In response to bleomycin treatment, lung fibroblasts but not macrophages have also been identified as active PAI-1 mRNA producers [36].

Altogether, these results indicate that inflammatory macrophages, but also other lung cell types, may contribute to the acute PAI antiprotease upregulation that takes place in response to silica. The significant involvement of PAI-2 is illustrated by mRNA measurements indicating a stronger upregulation of PAI-2 than PAI-1 in the lung tissue. However, because PAI-2 mRNA contains AU-rich sequences in its $3^{\prime}$ untranslated region, which have been shown to be responsible for instability of other transcripts $[40,41]$, it remains to be determined whether the changes in PAI-2 mRNA levels are followed by efficient increase of PAI-2 protein biosynthesis and secretion. Since the pulmonary and vascular compartments are in close proximity, one might speculate that these changes in lung PAIs observed in response to inorganic particles may to some extent be reflected in the vascular compartment. Our results are therefore consistent with the hypothesis developed by SEATON et al. [42] and recently corroborated by PeTERS $e t$ al. [43] that in addition to pulmonary effects, alterations in blood coagulability might be involved in the excess of cardiovascular mortality associated with urban particulate air pollution.

As previously described, sustained upregulations of both soluble and cell-associated PA activity were observed up to 120 days after silica treatment [7]. In contrast, BAL fluid PAI activity became undetectable 1 month after silica treatment while it was still substantial in control samples. The absence of soluble PAI activity at a later stage of the pathogenic process (fibrogenesis) might indicate a down regulation of PAI biosynthesis or a possible preferential extracellular matrix localization of the inhibitor. This latter possibility is supported by the high affinity of PAI-1 for several extracellular matrix proteins such as 
vitronectin and fibronectin that accumulate during the fibrogenic process. In particular, the sustained upregulation of PAI-1 mRNA levels noted up to day 30 in lung tissue indicates an active production of PAI- 1 protein that is not reflected in BAL fluid. PAI-1 antigen has been found in pneumocytes on interstitial pulmonary fibrosis (IPF) lung biopsy specimens [4] and PAI-1 protein and mRNA production were shown to colocalize with sites of fibrin deposition associated with bleomycin-induced lung fibrosis [36]. The interaction of PAI-1 with fibronectin and vitronectin could focus the antifibrinolytic activity at sites of extracellular matrix remodelling, thereby allowing the persistence of fibrin/fibronectin scaffolds. A persistent upregulation of both alveolar macrophage and total lung PAI-2 mRNA was also associated with the development of fibrosis. However, PAI-2, in contrast to PAI-1, has not been reported to bind extracellular matrix proteins in lung tissue. The potential role of this increased PAI-2 mRNA expression by lung tissue is, therefore, uncertain. However, as observed in freshly differentiated macrophages [18] and skin epithelial cells [19], induction of PAI-2 mRNA level at a later stage of the fibrogenesis might also reflect the silica-induced differentiation of pneumocytes necessary to resurface the injured parenchyma.

In conclusion, these observations, combined with changes in plasminogen activator activity reported previously [7], indicate that lesional upregulation of both plasminogen activator and plasminogen activator inhibitor soluble activity co-modulate the extravascular fibrin turnover, at least during the alveolitis stage. Our results indicate an early implication of plasminogen activator inhibitor-1 and suggest that cells other than alveolar macrophages contribute as sources of bronchoalveolar lavage fluid plasminogen activator inhibitor-1. Later in the disease process, opposite changes in plasminogen activator and plasminogen activator inhibitor were noted. While a sustained upregulation in bronchoalveolar lavage fluid plasminogen activator activity was previously demonstrated [7], we found no soluble bronchoalveolar lavage fluid plasminogen activator inhibitor activity which, together with plasminogen activator inhibitor-1 messenger ribonucleic acid findings, suggests a possible preferential localization of the inhibitor within extracellular matrix components. The involvement of plasminogen activator inhibitor- 2 which showed sustained messenger ribonucleic acid upregulation in macrophages and lung tissue is suggested in the control of pericellular proteolysis during both alveolitis and the later stages of silica-induced lung injury.

\section{References}

1. Idell S, James KK, Levin EG, et al. Local abnormalities in coagulation and fibrinolytic pathways predispose to alveolar fibrin deposition in the adult respiratory distress syndrome. J Clin Invest 1989; 84: 695-705.

2. Bertozzi P, Astedt B, Zenzius L, et al. Depressed bronchoalveolar urokinase activity in patients with adult respiratory distress syndrome. $N$ Engl J Med 1990; 322: 890-897.

3. Chapman HA, Allen CL, Stone OL. Abnormalities in pathways of alveolar fibrin turnover among patients with interstitial lung disease. Am Rev Respir Dis 1986; 133: 437-443.
4. Kotani I, Sato A, Hayakawa H, Urano T, Takada Y, Takada A. Increased procoagulant and antifibrinolytic activities in the lungs with idiopathic pulmonary fibrosis. Thromb Res 1995; 77: 493-504.

5. Brown LF, Dvorak AM, Dvorak HF. Leaky vessels, fibrin deposition and fibrosis: a sequence of events common to solid tumors and to many other types of disease. Am Rev Respir Dis 1989; 140: 1104-1107.

6. Gray AJ, Bishop JE, Reeves JT, Mecham RP, Laurent GJ. Partially degraded fibrin(ogen) stimulates fibroblast proliferation in vitro. Am J Respir Cell Mol Biol 1995; 12: 684-690.

7. Lardot CG, Huaux FA, Broeckaert FR, et al. Role of urokinase in the fibrogenic response of the lung to mineral particles. Am J Respir Crit Care Med 1998; 157 : 610-618.

8. Hart DA, Rehemtulla A. Plasminogen activators and their inhibitors: regulators of extracellular proteolysis and cell function. Comp Biochem Physiol B 1988; 90: 691-708.

9. Mayer M. Biochemical and biological aspects of the plasminogen activation system. Clin Biochem 1990; 23: $197-$ 211.

10. Hekman CM, Loskutoff DJ. Endothelial cells produce a latent inhibitor of plasminogen activators that can be activated by denaturants. J Biol Chem 1985; 260: 1158111587.

11. Parton LA, Warburton D, Laug WE. Plasminogen activator inhibitor type 1 production by rat type II pneumocytes in culture. Am J Respir Cell Mol Biol 1992; 6: 133-139.

12. Salonen EM, Vaheri A, Pollanen J, et al. Interaction of plasminogen activator inhibitor (PAI-1) with vitronectin. J Biol Chem 1989; 264: 6339-6343.

13. Pollanen J, Hedman K, Nielsen LS, Dano K, Vaheri A. Ultrastructural localization of plasma membrane-associated urokinase-type plasminogen activator at focal contacts. J Cell Biol 1988; 106: 87-95.

14. Belin D. Biology and facultative secretion of plasminogen activator inhibitor-2. Thromb Haemost 1993; 70: 144 147.

15. Chapman HA, Yang XL, Sailor LZ, Sugarbaker DJ. Developmental expression of plasminogen activator inhibitor type 1 by human alveolar macrophages. Possible role in lung injury. J Immunol 1990; 145: 3398-3405.

16. Belin D, Wohlwend A, Schleuning WD, Kruithof EK, Vassalli JD. Facultative polypeptide translocation allows a single mRNA to encode the secreted and cytosolic forms of plasminogen activators inhibitor 2. EMBO J 1989; 8: 3287-3294.

17. Nagayama M, Sato A, Hayakawa H, Urano T, Takada Y, Takada A. Plasminogen activators and their inhibitors in non-small cell lung cancer. Low content of type 2 plasminogen activator inhibitor associated with tumor dissemination. Cancer 1994; 73: 1398-1405.

18. Antalis TM, Dickinson JL. Control of plasminogenactivator inhibitor type 2 gene expression in the differentiation of monocytic cells. Eur J Biochem 1992; 205: 203-209.

19. Jensen PJ, Wu Q, Janowitz P, Ando Y, Schechter NM. Plasminogen activator inhibitor type 2: an intracellular keratinocyte differentiation product that is incorporated into the cornified envelope. Exp Cell Res 1995; 217: 6571.

20. Broeckaert F, Buchet JP, Huaux F, Lardot C, Lison D. Coal fly ash and copper smelter dust tumor necrosis factor alpha production by lung phagocytes after in vivo administration. J Toxicol Environ Health 1997; 51: 189 202. 
21. Schwartz BS, Bradshaw JD. Regulation of plasminogen activator inhibitor mRNA levels in lipopolysaccharidestimulated human monocytes. Correlation with production of the protein. J Biol Chem 1992; 267: 7089-7094.

22. Sawdey MS, Loskutoff DJ. Regulation of murine type 1 plasminogen activator inhibitor gene expression in vivo. Tissue specificity and induction by lipopolysaccharide, tumor necrosis factor-alpha, and transforming growth factor-beta. J Clin Invest 1991; 88: 1346-1353.

23. Leprince P, Rogister B, Moonen G. A colorimetric assay for the simultaneous measurement of plasminogen activators and plasminogen activator inhibitors in serum-free conditioned media from cultured cells. Anal Biochem 1989; 177: 341-346.

24. Schnyder J, Marti R, Cooper PH, Payne TG. Spectrophotometric method to quantify and discriminate urokinase and tissue-type plasminogen activators. Anal Biochem 1992; 200: 156-162.

25. Declerck PJ, Verstreken M, Collen D. Immunoassay of murine t-PA, u-PA and PAI-1 using monoclonal antibodies raised in gene-inactivated mice. Thromb Haemost 1995; 74: 1305-1309.

26. Driscoll KE, Maurer JK, Poynter J, Higgins J, Asquith T, Miller NS. Stimulation of rat alveolar macrophage fibronectin release in a cadnium chloride model of lung injury and fibrosis. Tox Appl Pharmacol 1992; 116: 30-37.

27. Prendergast G, Diamond L, Dahl D, Cole M. The c-myc-regulated gene mr1 encodes plasminogen activator inhibitor 1. Mol Cell Biol 1990; 10: 1265-1269.

28. Eitzman DT, McCoy RD, Zheng X, et al. Bleomycin-induced pulmonary fibrosis in transgenic mice that either lack or overexpress the murine plasminogen activator inhibitor-1 gene. J Clin Invest 1996; 97: 232-237.

29. Piguet PF, Collart MA, Grau GE, Sappino AP, Vassalli P. Requirement of tumour necrosis factor for development of silica-induced pulmonary fibrosis. Nature 1990; 344: 245-247.

30. Gyetko MR, Shollenberger SB, Sitrin RG. Urokinase expression in mononuclear phagocytes: cytokine-specific modulation by interferon-gamma and tumor necrosis factor-alpha. J Leukoc Biol 1992; 51: 256-263.

31. Hamilton JA, Wojta J, Gallichio M, McGrath K, Filonzi EL. Contrasting effects of transforming growth factor-beta and IL-1 on the regulation of plasminogen activator inhibitors in human synovial fibroblasts. J Immunol 1993; 151: 5154-5161.
32. Emeis JJ, Kooistra T. Interleukin 1 and lipopolysaccharide induce an inhibitor of tissue-type plasminogen activator in vivo and in cultured endothelial cells. J Exp Med 1986; 163: 1260-1266.

33. Callis AH, Sohnle PG, Mandel GS, Wiessner J, Mandel NS. Kinetics of inflammatory and fibrotic pulmonary changes in a murine model of silicosis. J Lab Clin Med 1985; 105: 547-553.

34. Schimmelpfeng J, Seidel A. Cytotoxic effects of quartz and chrysotile asbestosis: in vivo interspecies comparison with alveolar macrophages. J Toxicol Environ Health 1991; 33: 131-140.

35. Huaux F, Lasfargues G, Lauwerys R, Lison D. Lung toxicity of hard metal particles and production of interleukin1 , tumor necrosis factor-alpha, fibronectin and cytostatin-c by lung phagocytes. Toxicol Appl Pharmacol 1995; 132: 53-62.

36. Olman MA, Mackman N, Gladson CL, Moser KM, Loskutoff DJ. Changes in procoagulant and fibrinolytic gene expression during bleomycin-induced lung injury in the mouse. J Clin Invest 1995; 96: 1621-1630.

37. Triebel S, Blaser J, Gote T, et al. Evidence for the tissue inhibitor of metalloproteinases-1 (TIMP-1) in human polymorphonuclear leukocytes. Eur J Biochem 1995; 231: 714-719.

38. Devarajan P, Johnson JJ, Ginsberg SS, Van Wart HE, Berliner N. Structure and expression of neutrophil gelatinase cDNA. Identity with type IV collagenase from HT1080 cells. J Biol Chem 1992; 267: 25228-25232.

39. Hagood JS, Olman MA, Godoy JA, Rivera KE, Fuller GM. Regulation of type I plasminogen activator inhibitor by fibrin degradation products in rat lung fibroblasts. Blood 1996; 87: 3749-3757.

40. Nanbu R, Menoud PA, Nagamine Y. Multiple instability-regulating sites in the $3^{\prime}$ untranslated region of the urokinase-type plasminogen activator mRNA. Mol Cell Biol 1994; 14: 4920-4928.

41. Shaw G, Kamen R. A conserved AU sequence from the 3' untranslated region of GM-CSF mRNA mediates selective mRNA degradation. Cell 1986; 46: 659-667.

42. Seaton A, MacNee W, Donaldson K, Godden D. Particulate air pollution and acute health effects. Lancet 1995; 345: 176-178.

43. Peters A, Doring A, Wichmann HE, Koenig W. Increased plasma viscosity during an air pollution episode: a link to mortality? Lancet 1997; 349: 1582-1587. 